\title{
ARTIGO
}

\section{Cooperativismo na Bahia: uma perspectiva histórica}

\author{
Cooperativism in Bahia: a historical perspective
}

\begin{abstract}
Nilton Vasconcelos, D.Sc.
Professor Titular do Instituto Federal de Educação, Ciência e Tecnologia - IFBA. Ex-secretário de Estado de Trabalho da Bahia (2007-2014). Doutor em Administração Pública pela Escola de Administração da Universidade Federal da Bahia, em 2002.
\end{abstract}

RESUMO: O cooperativismo no estado da Bahia, no período compreendido entre fins do século XIX e meados do século XX, tem sua trajetória resgatada por meio de levantamento em publicações de época. Um estudo exploratório que apresenta aspectos pouco conhecidos sobre essas experiências associativas no estado e sobre as iniciativas governamentais no fomento ao cooperativismo. Os resultados relatados no presente texto apontam para uma agenda de pesquisa que tenha como objetivo o aprofundamento da compreensão sobre aquelas práticas.

ABSTRACT: Cooperativism in the State of Bahia, in the period between the end of the 19th century and the middle of the 20th century, has its trajectory rescued through historical documents published during that time period. It's an exploratory study that presents little-known aspects about these associative experiences in the State of Bahia and the role of government action in promoting cooperativism. The results reported in this text indicates a need to a research agenda that aims to deepen the understanding of cooperativism practices.

RESUMEN: El cooperativismo en el estado de Bahía, en el período comprendido entre fines del siglo XIX y mediados del siglo XX, tiene su trayectoria rescatada a través de documentos históricos publicados durante ese período. Se trata de un estudio exploratorio que presenta aspectos poco conocidos sobre estas experiencias asociativas en el Estado de Bahía y el papel de la acción gubernamental en la promoción del cooperativismo. Los resultados reportados en este texto indican la necesidad de una agenda de investigación que busque profundizar en la comprensión de las prácticas del cooperativismo.

Laborare. Ano IV, Número 6, Jan-Jun/2021, pp. 90-105. ISSN 2595-847X. https://revistalaborare.org/ DOI: https://doi.org/10.33637/2595-847x.2021-65 


\section{INTRODUÇÃO}

Cento e setenta e seis anos nos separam da fundação da Cooperativa de Consumo de Rochdale, na Inglaterra. Desde então, o cooperativismo expandiu-se pelo mundo, tendo chegado ao Brasil algumas décadas depois daquela experiência pioneira.

Cinquenta anos após aquele evento, em 1895, surge a Aliança Cooperativa Internacional (ACI), sendo uma das primeiras organizações de representação a participar do Sistema Nações Unidas. Ainda no âmbito das organizações multilaterais de cooperação, em 2002, a Conferência Geral da Organização Internacional do Trabalho (OIT) fez aprovar a Recomendação de n. ${ }^{\circ} 193$ sobre a Promoção de Cooperativas, incitando os estados-membros a implementar Políticas Públicas para a promoção do cooperativismo. Segundo a Recomendação n. ${ }^{\circ}$ 193/2002 da OIT, o termo "cooperativa" significa "associação autônoma de pessoas que se unem voluntariamente para atender a suas necessidades e aspirações comuns, econômicas, sociais e culturais, por meio de empreendimento de propriedade comum e de gestão democrática". Naturalmente, em cada país membro, as cooperativas estão reguladas por normativas próprias, contudo, o conceito básico deve ser considerado. Este conceito é aquele adotado pela ACI, e reproduzido pela sua afiliada Organização das Cooperativas das Américas (OCA) na Lei Marco para as cooperativas de América Latina (ACI AMÉRICAS, 2009).

O Anuário do Cooperativismo Brasileiro, edição 2019, produzido pela Organização de Cooperativas do Brasil (OCB) contabiliza três milhões de cooperativas no mundo, 6,8 mil do Brasil, com aproximadamente 15 milhões de cooperados. Por sua vez, a União Nacional das Cooperativas da Agricultura Familiar e Economia Solidária (Unicafes), fundada em 2005, registra 700 cooperativas vinculadas às 19 unidades regionais. As cooperativas têm, indiscutivelmente, grande impacto econômico e social no mundo, e em nosso país, em particular, com aproximadamente 150 anos de atuação.

Aprofundar o conhecimento sobre o cooperativismo no Brasil, e especificamente, do florescimento do cooperativismo na Bahia, desde o século XIX até meados do século $\mathrm{XX}$, é o desafio que orientou o estudo no qual se fundamenta este texto.

A pesquisa empreendida objetivou identificar relatos em documentação de época sobre experiências cooperativistas baianas que indicassem iniciativas primordiais no estado, as quais poderiam ter influenciado a conformação atual dessas organizações. Procurou-se, ainda, identificar o tratamento dado ao tema do cooperativismo, especialmente anterior à conformação das sociedades cooperativas.

Laborare. Ano IV, Número 6, Jan-Jun/2021, pp. 90-105. ISSN 2595-847X. https://revistalaborare.org/ DOl: https://doi.org/10.33637/2595-847x.2021-65 
A pesquisa documental foi realizada em registros históricos digitalizados e disponíveis ao público. Após a consolidação das informações preliminares, e análises empreendidas, novos objetivos de pesquisa poderão explorar as razões da descontinuidade daquelas experiências, as orientações práticas que predominaram na fundação dessas entidades e o seu vínculo com as concepções pioneiras na Inglaterra, bem como na Alemanha e Itália, em particular, além de avaliar o grau de autonomia em relação ao Estado brasileiro, entre outros aspectos.

A base de dados para o levantamento considerou jornais e revistas publicados na Bahia, bem como relatórios e mensagens do Executivo Provincial/Estadual, englobando um lapso de tempo de aproximadamente setenta e cinco anos. Para tanto, utilizou-se ferramentas digitais específicas do acervo da Biblioteca Nacional, sendo encontradas referências ao cooperativismo ou a cooperativas em 27 publicações, totalizando 62 diferentes edições, entre os anos de 1871 e $1948 .{ }^{1}$

$\mathrm{Na}$ documentação, são encontradas informações com diferentes configurações: pequenas notas, editais de convocação de reuniões, notícias, anúncios publicitários, artigos analíticos, relatos de experiências, trechos de relatórios governamentais, enfim, fragmentos que permitissem identificar com mais ou menos detalhes, a ocorrência de iniciativas associativas designadas como de natureza cooperativa.

Complementarmente, foram consultadas publicações diversas, normas legais, livros publicados à época, de modo a contextualizar as informações, ou acrescentar dados que garantissem melhor compreensão dos fenômenos estudados.

A seguir, é feita uma sistematização de informações amplamente difundidas na literatura sobre o cooperativismo e o marco legal, e as primeiras experiências cooperativas no Brasil. Veremos que os achados deste estudo exploratório apontam para a necessidade de aprofundar as pesquisas neste campo.

\section{O SURGIMENTO DO COOPERATIVISMO E O SEU MARCO LEGAL}

O cooperativismo no Brasil é marcado, nos últimos 50 anos, pela criação do sistema de organizações cooperativas a partir da Lei n. $^{\circ}$ 5.764/71. Um marco importante, seja pela legislação que estabelece os parâmetros da ação cooperativista, seja pela multiplicação de iniciativas no último quarto do século XX. A importância daquele

\footnotetext{
1 Foi identificado um total de 358 documentos - Jornais, Relatórios, Mensagens, na Bahia, no período que abrange fins do século XIX a metade do século XX, nos quais, em apenas 26 deles foram encontradas 434 vezes a menção à palaura "cooperativa" - muitas vezes em anúncios publicitários; outras 53 ocorrências mencionavam o termo "cooperativismo".
}

Laborare. Ano IV, Número 6, Jan-Jun/2021, pp. 90-105. ISSN 2595-847X. https://revistalaborare.org/ DOI: https://doi.org/10.33637/2595-847x.2021-65 
marco não deve minimizar o surgimento, nos anos dois mil, de políticas públicas de incentivo à economia solidária e as experiências denominadas de cooperativismo popular, e à agricultura familiar, movimento este que provocou uma nova onda de cooperativas que romperam, em certo sentido, com a tradição representada pelas organizações que surgiram com a definição da Política Nacional de Cooperativismo e da instituição do regime jurídico das sociedades cooperativas, em 1971.

Para efeito deste trabalho, vale destacar registros, na literatura especializada, de iniciativas governamentais muito anteriores à Política Nacional e que tiveram, a seu tempo, influência na trajetória do cooperativismo no país. Apontado como primeiro texto legal que dispõe sobre a matéria, o Decreto n. ${ }^{\circ} 799$, de 06/01/1903, embora tratasse fundamentalmente de facultar a organização de sindicatos "aos profissionais da agricultura e indústrias rurais", admitia, complementarmente, que tais sindicatos poderiam criar caixas rurais de crédito, bem como cooperativas de produção e de consumo ${ }^{2}$.

Em seguida, o Decreto-Lei n. ${ }^{\circ} 1.637$, de 05/01/1907, faculta a criação de sindicatos de quaisquer profissões, assim como de cooperativas ${ }^{3}$. Diferentemente do texto de 1903, este Decreto-Lei não vincula a criação de cooperativas aos sindicatos e, em dois capítulos distintos, estabelece as condições básicas para a existência dessas tipologias organizacionais ${ }^{4}$.

A partir daquele marco, diversos decretos e leis tratam do cooperativismo de forma pontual. Em 1932, o Decreto n. 22.239 consagrava princípios do sistema cooperativista, reformando o mencionado decreto de 1907, revogado em 1934, voltando a viger em 1938 e alterado em 1945 (WACILICZ e OLIVEIRA FILHO, 2015).

Não é objetivo deste texto fazer uma análise da legislação brasileira até os dias atuais, avançando sobre a segunda metade do século XX e o século XXI, ficando o texto restrito, portanto, ao limite temporal já citado.

20 artigo 10 do referido decreto estabelecia que: "A função dos sindicatos nos casos de organização de caixas rurais de crédito agrícola e de cooperativa de produção ou de consumo, de sociedade de seguros, assistência etc., não implica responsabilidade direta dos mesmos nas transações, nem os bens nela empregados ficam sujeitos ao disposto no n.o 8, sendo a liquidação de tais organizações regida pela lei comum das sociedades civis".

3 O Decreto-Lei n. 1637/1907, assim referido no Decreto n.ㅇ 22.239 de 19 de dezembro de 1932, que o reformou, é também referido como Decreto nos registros da Câmara dos Deputados em https://www2.camara.leg.br/. Há, ainda, inúmeros textos que denomina de Lei.

4 A Constituição Federal de 1891, já assegurava aos trabalhadores o direito de se associarem em cooperativas e em sindicatos.

Laborare. Ano IV, Número 6, Jan-Jun/2021, pp. 90-105. ISSN 2595-847X. https://revistalaborare.org/ DOI: https://doi.org/10.33637/2595-847x.2021-65 
Por mera casualidade, o mencionado recorte coincide com o que escrevia Valdiki Moura, em 1947, em seu importante texto "Notícia do Cooperativismo Brasileiro", que reproduzo abaixo:

Há quem pretenda dividir o movimento cooperativo brasileiro em duas fases, uma compreendida entre 1911 e 1915, e a outra de 1926 aos nossos dias, classificação que me não parece exata pelos seguintes motivos: 1) há que levar em conta, pelo menos, o período anterior a 1911, desde as tentativas levadas a efeito nos últimos dias do Império e primeiros da República, sem esquecer a primeira lei cooperativista de 1907 e suas consequências materiais; e 2) porque, depois da lei n. ${ }^{\circ} 22.239$ de 1932, o movimento tomou tal ímpeto e cresceu em ritmo tão progressivo, que teríamos de contar outro período a partir deste ano. Orientaria assim meu estudo, se tivesse de tomar o critério meramente cronológico do desenvolvimento cooperativista nacional: 1) das últimas décadas do Império a 1925; 2) de 1926 a 1932; e 3) de 1933 aos dias atuais (MOURA, 1947, p. 1-2).

O contato com a produção de Valdiki Moura ${ }^{5}$ deu-se ao longo dos estudos empreendidos e cujos resultados são aqui apresentados. A menção à "primeira lei cooperativista", como passou a ser consagrada na literatura, não o impediu de referir ao período imperial e à virada republicana. Efetivamente, houve decretos imperiais que tratavam do funcionamento de cooperativas, antes mesmo daquela, sempre mencionada, Sociedade Cooperativa Econômica dos Funcionários Públicos de Ouro Preto, exaltada como a primeira cooperativa de consumo do Brasil, fundada no ano de 1889 (PINHEIRO, 2008; BRASIL, 2006).

Veremos que outras experiências ocorreram, sobretudo, no Rio de Janeiro e na Bahia, que merecem a devida atenção, inclusive quanto às suas características, e motivações para o seu surgimento. Considerando a tentativa de estabelecimento de fases do cooperativismo nacional, referidas no trecho acima, poderíamos descrever o presente trabalho como uma incursão à pré-história do cooperativismo brasileiro e baiano, em especial, anterior àquelas manifestações mais conhecidas. Contudo, este estudo tem por objetivo projetar-se até fins dos anos 1940.

O marco temporal escolhido decorre da leitura e análise do Catálogo de Cooperativas Baianas, publicado em 2012 pelo Governo do Estado, que registrou um total de 1.796 cooperativas. Reconhecidamente incompleto, não só por possíveis omissões, mas também por registrar cooperativas possivelmente extintas, a publicação expressou a

5 Valdiki Moura é um autor baiano com vasta produção intelectual sobre o cooperativismo, que está por merecer, oportunamente, o devido resgate. Da sua obra destacaria, além de "Notícia do cooperativismo brasileiro", de 1947, "Bibliografia Brasileira do Cooperativismo: pequeno ensaio de sistematização", de 1951; e "Democracia Econômica: Introdução à Economia Cooperativa", de 1942.

Laborare. Ano IV, Número 6, Jan-Jun/2021, pp. 90-105. ISSN 2595-847X. https://revistalaborare.org/ DOI: https://doi.org/10.33637/2595-847x.2021-65 
tentativa de síntese do quadro então disponível, sendo o Catálogo apresentado como "estímulo inicial para que essas instituições atualizem seu cadastro" (BAHIA, 2012).

Do levantamento das sociedades cooperativas listadas, apenas duas delas haviam sido fundadas na primeira metade do século XX. Mais precisamente, em 1942 e 1943, ambas do ramo agropecuário, e sobre as quais não se dispunha de informações sobre seu efetivo funcionamento. Considerando, ainda, as cooperativas incluídas no Catálogo, apenas 27 teriam sido constituídas antes da Lei n. ${ }^{\circ}$ 5.764/1971.

Assim, o estudo ateve-se à busca de evidências de experiências cooperativas anteriores àquelas registradas no Catálogo.

\section{ORIGENS DO COOPERATIVISMO NA BAHIA}

Nesta seção, será feita uma exposição cronológica dos achados nas publicações pesquisadas, seja a menções sobre o cooperativismo ou a cooperativas específicas. Alternadamente, outras publicações são consideradas para efeito de contextualização ou complementação de dados. Nem sempre, contudo, o leitor encontrará uma linha contínua, uma sequência lógica nas informações, seja porque ainda não foram desvendadas as correlações entre os fenômenos ou não foram identificadas as contradições presentes nesse processo histórico. Essas lacunas ou incompletudes são, por outro lado, consequências dos passos que foram dados nesta caminhada.

A primeira referência sobre o cooperativismo na Bahia nos documentos pesquisados é encontrada nos "Anexos ao Relatório" dos Trabalhos do Conselho Interino de Governo da Bahia, com o que o presidente da Província da Bahia, o Barão de São Lourenço, abre os trabalhos da Assembleia da Bahia, em primeiro de março de 1871. $\mathrm{O}$ documento reúne nove relatórios de áreas específicas, dentre os quais, do Imperial Instituto Bahiano de Agricultura, de 10 de fevereiro do mesmo ano.

O referido Relatório apresenta um diagnóstico sumário das limitações da ação do Estado frente à "lavoura" e à "criação", sendo impotente para tornar lucrativa a atividade agropecuária, para concluir com uma indagação: "As associações poderiam tentar as reformas indispensáveis, mas como despertá-las e promovê-las sem a prévia educação que patenteie as vantagens da ação cooperativa e forneça auxiliares seguros para a consumação da empresa?" A solução apontada é a "instrução agrícola". Deveria o Governo Imperial dedicar-se a formar pessoas com capacidade de administrar essas atividades, numa referência superficial à ação cooperada.

Laborare. Ano IV, Número 6, Jan-Jun/2021, pp. 90-105. ISSN 2595-847X. https://revistalaborare.org/ DOI: https://doi.org/10.33637/2595-847x.2021-65 
É uma referência genérica, mas de todo modo, elogiosa, pressupondo haver uma superioridade da forma cooperativa comparativamente à sistemática predominante no enfrentamento dos problemas da atividade agropecuária no país. O Relatório dá muita ênfase à necessidade de uma abordagem técnica tendo em vista a situação "assustadora" da lavoura, o "equilíbrio instável", a falta de crédito, propriedades mal administradas etc.

Ainda no século XIX, mais precisamente no ano de 1876, o Diário de Notícias, jornal publicado na capital baiana, em sua edição de 15 de novembro, rememorava, em nota na sua primeira página, que, há mais de 30 anos, vinte e oito operários ingleses criaram a Cooperativa de Consumo de Rochdale, e que contava então com $10 \mathrm{mil}$ membros, sólida administração e excelentes resultados.

Naquele mesmo ano de 1876, a edição de 25 de setembro da Gazeta da Bahia noticiava a criação, na França, da Sociedade Cooperativa Universal. Teria sido fundada por grande número de industriais, tendo à frente o Sr. H. Regnier, dizia o noticioso, cuja sociedade procuraria estreitar as relações Brasil/França.

O interesse do governo imperial do Brasil sobre o cooperativismo é expressa na notícia do Correio da Bahia, de 18 de julho de 1877, durante a terceira excursão internacional de D. Pedro II. Ao visitar a França, o Imperador demonstrou interesse em conhecer a fábrica de chocolates do deputado Menier, solicitando que discorresse sobre a associação cooperativa que ele instituiu para os seus empregados.

No Brasil, contudo, a formação de cooperativas já havia iniciado. A Regente Princesa Isabel, em abril de 1876, edita um decreto autorizando o funcionamento de uma Cooperativa de Consumo ${ }^{6}$ no Rio de Janeiro, e no ano seguinte, um novo decreto, alterando seu estatuto ${ }^{7}$, modificação essa que mereceu destaque na imprensa baiana. Assim como a autorização para funcionar a Cooperativa de Consumo de Pão, em Niterói ${ }^{8}$.

\footnotetext{
6 A referida cooperativa teve suas bases organizativas divulgadas em 1875, no Jornal do Commercio, de 19 de dezembro daquele ano, editado no Rio de Janeiro, fazendo publicar um texto de apresentação da Sociedade Cooperativa assinado por Dr. Castro Lopes. Neste texto, menciona as experiências na Inglaterra e na Alemanha, explicita a área de atuação da cooperativa onde seriam instalados os armazéns para comercializar gêneros secos e molhados, indica os principais traços definidos em Estatuto, ressaltando que seu funcionamento dependeria da aprovação do governo imperial. Tendo sido efetivamente aprovada por Decreto n. 06.186 de 26 de abril de 1876.

7 Decreto n.ㅇ 6.661, de 14 de agosto de 1877, através do qual "A Princesa Imperial Regente, em Nome do Imperador, Atendendo ao que requereu a Companhia Cooperativa de Consumo, devidamente representada, e de conformidade com o parecer da Seç̧ão dos Negócios do Império do Conselho de Estado exarado em Consulta de 9 de Julho último, Há por bem Aprovar a reforma dos estatutos da referida companhia".

8 A Companhia Cooperativa de Consumo de Pão foi autorizada a funcionar através do Decreto Imperial n.으 6.447, de 30 de dezembro de 1876.
}

Laborare. Ano IV, Número 6, Jan-Jun/2021, pp. 90-105. ISSN 2595-847X. https://revistalaborare.org/ DOI: https://doi.org/10.33637/2595-847x.2021-65 
Muitas destas notícias eram publicadas nos jornais baianos no ano de 1876, a exemplo de $\mathrm{O}$ Monitor e Correio da Bahia. O jornal cachoeirano O Guarany também noticiava as virtudes do cooperativismo e o avanço dessas organizações em outros países.

Pode-se perceber que havia uma repercussão sobre o cooperativismo e suas práticas na Europa e no Brasil, especialmente na Corte, informações em geral positivas e que antecipa o noticiário sobre a formação de sociedades cooperativas.

De fato, a primeira informação que dá conta da existência de uma Cooperativa na Bahia só é encontrada no Pequeno Jornal, edição de 4 de março de 1890, no nascedouro da República. Naquela edição, registra-se o resultado da reunião da Sociedade Cooperativa dos Alfaiates, que por maioria dos sócios aprova novos artigos para o estatuto, por terem sido considerados nulos os estatutos vigentes até então9. Como se pode depreender, a cooperativa já existia anteriormente a esta data, mas no levantamento inicial não se obteve informação sobre seu funcionamento e grau de regularização face à norma legal então vigente.

Nova referência sobre a Cooperativa dos Alfaiates é encontrada no Jornal de Notícias, também editado em Salvador, em 10 de janeiro de 1891, sendo apenas para anunciar para o dia seguinte uma reunião da Sociedade União Cooperativa dos Alfaiates.

Ao longo das duas décadas seguintes, o noticiário dos jornais baianos refere-se a expressivo número de organizações cooperativas, sejam elas de iniciativa da sociedade ou em desdobramento da política de incentivo do governo estadual. $\mathrm{O}$ quadro abaixo sistematiza as informações encontradas, os periódicos, edições e denominação da sociedade cooperativa.

No mencionado Quadro observa-se, que as cooperativas de consumo são mais frequentes, tais como a do Regimento Militar da Bahia, a cooperativa Universal, a União Sociocrática, a cooperativa de consumo dos Funcionários Públicos da Bahia, a Cooperativa Operária da Bahia.

Verifica-se, ainda, a ocorrência de sociedades cooperativas voltadas para o crédito urbano, a exemplo da Caixa Popular, de 1915, e da Cooperativa Banco de Crédito Popular, de 1948. São iniciativas distintas daquelas fomentadas pelo Governo do Estado, entre os anos 1925 e 1930, conforme veremos adiante.

9 A nota menciona ainda que participou da reunião o "iniciador da ideia", e que entre as deliberações havidas foi nomeada uma superintendência com três sócios, e decidiu-se desligar um sócio, devolvendo-lhe o capital que aportou, tendo sido marcada nova reunião para o domingo seguinte.

Laborare. Ano IV, Número 6, Jan-Jun/2021, pp. 90-105. ISSN 2595-847X. https://revistalaborare.org/ DOI: https://doi.org/10.33637/2595-847x.2021-65 
Duas cooperativas têm escolas como base para sua organização, a Cooperativa de Mutualidade Escola de Aprendizes Artífices, de 1912, e a Cooperativa do Colégio da Bahia, de 1948. São influenciadas, no entanto, por dois movimentos distintos, sendo esta última decorrente de política estadual de fomento ${ }^{10}$.

QUADRO: Cooperativas baianas de 1871-1948

\begin{tabular}{|c|c|c|}
\hline Data & Cooperativa mencionada & Publicação \\
\hline 04/03/1890 & $\begin{array}{l}\text { Noticia a reunião da Sociedade Cooperativa dos } \\
\text { Alfaiates }\end{array}$ & Pequeno Jornal \\
\hline $11 / 03 / 1905$ & Cooperativa da Imprensa Econômica & Jornal A Semana \\
\hline $30 / 07 / 1908$ & Cooperativa de Consumo do Regimento Militar da Bahia & A Revista do Brasil \\
\hline $10 / 10 / 1902$ & Cooperativa Universal de Produção e Consumo & Gazeta de Notícias \\
\hline 1903 & Cooperativa Alcoólica de Santo Amaro & $\begin{array}{l}\text { Mensagem do } \\
\text { Governador da Bahia }\end{array}$ \\
\hline 23/10/1912 & $\begin{array}{l}\text { Cooperativa de mutualidade Escola de Aprendizes } \\
\text { Artífices }\end{array}$ & Gazeta de Notícias \\
\hline 08/01/1913 & $\begin{array}{l}\text { Cooperativa Universal de Produção e Consumo União } \\
\text { Sociocrática }\end{array}$ & Gazeta de Notícias \\
\hline $05 / 12 / 1912$ & Cooperativa do Centro Operário da Bahia & Gazeta de Notícias \\
\hline $26 / 03 / 1913$ & União Cooperativa Postal & Gazeta de Notícias \\
\hline $18 / 06 / 1914$ & $\begin{array}{l}\text { Cooperativa de Consumo dos Funcionários Públicos da } \\
\text { Bahia }\end{array}$ & A Notícia \\
\hline $02 / 11 / 1914$ & Sociedade Cooperativa a "União" & A Notícia \\
\hline $02 / 01 / 1915$ & A Sociedade Cooperativa Caixa Popular & A Notícia \\
\hline $02 / 01 / 1915$ & $\begin{array}{l}\text { Sociedade de Pecúlios por Mutualidade e Cooperativa } \\
\text { Predial }\end{array}$ & A Notícia \\
\hline $29 / 11 / 1915$ & Sociedade Cooperativa A Vencedora & A Notícia \\
\hline 14/01/1919 & Cooperativa Alcoólica da Bahia & A Hora \\
\hline $21 / 05 / 1919$ & Cooperativa Operária & A Hora \\
\hline $11 / 01 / 1921$ & Cooperativa da Colônia dos Pescadores de Amaralina & A Manhã \\
\hline 07/1939 & Cooperativa de Caprinos e Ovinos & $\begin{array}{l}\text { Bahia Tradicional e } \\
\text { Moderna }\end{array}$ \\
\hline $07 / 1939$ & Cooperativa Instituto de Pecuária da Bahia & $\begin{array}{l}\text { Bahia Tradicional e } \\
\text { Moderna }\end{array}$ \\
\hline 1942 & Cooperativa Central de Cacauicultores Bahianos & $\begin{array}{l}\text { Boletim da } \\
\text { Cooperativa Central }\end{array}$ \\
\hline $11 / 03 / 1948$ & Cooperativa dos Empregados da Souza Cruz & O Momento \\
\hline $23 / 04 / 1948$ & Cooperativa do Colégio da Bahia & O Momento \\
\hline $16 / 05 / 1948$ & Cooperativa dos Plantadores de Cana & O Momento \\
\hline $17 / 06 / 1948$ & Cooperativa Mista de Agricultores & O Momento \\
\hline
\end{tabular}

10 No caso das Escolas de Aprendizes e Artífices, o Decreto Federal n.o 9.070, de 25 de outubro de 1911, que aprovou o Regimento dessas unidades, estabeleceu no seu artigo 28 que os diretores deveriam promover a organização de associações cooperativas e de mutualidade entre os aprendizes, definindo prazo para regulamentação.

Laborare. Ano IV, Número 6, Jan-Jun/2021, pp. 90-105. ISSN 2595-847X. https://revistalaborare.org/ DOI: https://doi.org/10.33637/2595-847x.2021-65 


\begin{tabular}{l|l|l}
\hline $\begin{array}{l}21 \mathrm{e} \\
22 / 07 / 1948\end{array}$ & $\begin{array}{l}\text { Cooperativa dos Trabalhadores da Fábrica da Suerdick, } \\
\text { em Maragogipe }\end{array}$ & O Momento \\
\hline $24 / 08 / 1948$ & $\begin{array}{l}\text { Cooperativa Banco de Crédito Popular, com agências em } \\
\text { Itajuípe, Ibicaraí e Coaraci }\end{array}$ & O Momento \\
\hline \hline
\end{tabular}

Fonte: Elaboração própria.

Como não poderia deixar de ser, são encontrados registros de cooperativas rurais, o que não deve causar estranheza pelo fato de que foi o Ministério da Agricultura, assim como, nas respectivas secretarias estaduais, que sediou o organismo governamental encarregado da disseminação do cooperativismo ${ }^{11}$. Temos, assim, a cooperativa "Alcoólica" de Santo Amaro, vinculada à agroindústria da cana de açúcar; a Cooperativa de Caprinos e Ovinos; a Cooperativa do Instituto de Pecuária da Bahia e as Cooperativas que reuniram produtores de cacau.

A lista dos achados da pesquisa é complementada com outras iniciativas sobre as quais este esforço exploratório não detectou maiores informações, sem desmerecer a sua relevância, a exemplo da Cooperativa da Colônia dos Pescadores de Amaralina.

No panorama nacional, durante os primeiros anos do século XX, o Ministério da Agricultura elabora "mapa das cooperativas existentes, identificando cerca de trezentas associações, mais ou menos cooperativas...” (BRITTO, 1924).

Por volta dos anos 1914-1916, ainda segundo Britto (1924), houve uma priorização do estímulo ao crédito agrícola por meio das "Caixas Raiffeisen", baseado na experiência alemã de cooperativas de crédito rural, em detrimento das demais modalidades ou ramos do cooperativismo.

Em linha com as iniciativas do Ministério da Agricultura, em 1925, na Bahia, o governador Francisco Marques de Góes Calmon, em seu relatório governamental anual à Assembleia, a exemplo do movimento que se desenvolve nacionalmente de estímulo ao cooperativismo rural, refere-se ao cultivo do fumo:

É uma das grandes lavouras do estado, com papel predominante no seio da nação. Infelizmente, também é, em geral, rotineira por ser a lavoura do pobre e também proletária.

Todavia, foi nela que, entre nós, nasceu o cooperativismo, o princípio associativo.

11 Em 1933, foi instituída a Diretoria do Sindicalismo Cooperativista no Ministério da Agricultura, subordinando a Secção de Crédito Agrícola que já desenvolvia ações de difusão do cooperativismo. Nos anos quarenta, já eram registrados em vários estados órgãos de assistência ao cooperativismo e à economia rural (MOURA, 1947).

Laborare. Ano IV, Número 6, Jan-Jun/2021, pp. 90-105. ISSN 2595-847X. https://revistalaborare.org/ DOI: https://doi.org/10.33637/2595-847x.2021-65 
No mesmo relatório de janeiro de 1925 , volta ao tema do cooperativismo às páginas 207/208:

Em conformidade com as promessas com que acreditei pudesse exercer minha ação de governo desde que assumi os encargos da administração pública, cogitei de fazer efetivo no Estado o cooperativismo, não só de consumo, como de produção e crédito.

Fomentei larga propaganda por intermédio de publicações feitas no Diário Oficial do Estado. Convencido de que, na ausência, entre nós, de instituições de crédito bancário somente pela cooperação direta das classes ou na coletiva dos indivíduos, poder-se-ia criar a força financeira capaz de animar e ativar as verdadeiras iniciativas do trabalho, envidei esforços afim de que, nas Fábricas e Usinas e centros de produção industrial e agrícola, se compreendesse a imprescindibilidade da ação solidária, sobretudo para a formação das cooperativas de consumo e de crédito..."

Ressalta, ainda, no seu Relatório, o apoio do ministro Miguel Calmon ${ }^{12}$, na indicação de especialistas sobre o cooperativismo, resultando na instalação de treze caixas rurais de crédito (sistema Raiffeisen), nos municípios de Itabuna, Santo Amaro, São Gonçalo dos Campos, Feira de Santana, Cachoeira, São Félix, Muritiba, Nazaré, Santo Antônio de Jesus, Amargosa, Alagoinhas, Bonfim e Serrinha.

Novamente, no relatório de 1926 à Assembleia, o governador Góes Calmon reserva um capítulo específico para o Crédito Agrícola e Cooperativismo (p. 239) ressaltado ser "notório o desenvolvimento continuado do crédito popular e agrícola", que em um ano as Caixas Rurais no sistema Raiffeisen saíram de 13 para 38, acrescentando a essas um banco Luzzatti ${ }^{13}$, sendo que catorze unidades não estão funcionando por falta de "material de escrita" que o governo obrigou-se a fornecer.

Para promover o cooperativismo de crédito, o governo criou a Comissão Central das Caixas Rurais, que tinha entre seus membros aquele que seria reconhecido como grande educador, o Prof. Anísio Teixeira ${ }^{14}$. Cabia à Comissão coordenar o esforço de instalação de novas Caixas, o que foi feito através da publicação mensal do jornal "Caixas Ruraes", de propaganda do sistema Raiffeisen.

12 Miguel Calmon du Pin e Almeida (1879-1935), engenheiro baiano, foi deputado federal pela Bahia, ministro da Indústria, Viação e Obras Públicas de 1906 a 1909 e ministro da Agricultura de 1922 a 1926.

13 Refere-se ao sistema de crédito cooperativo desenvolvido pelo italiano Luigi Luzzatti.

14 Integrava ainda o esforço os senhores Alberto Fraga, então deputado federal, e o Sr. Inácio Tosta Filho, comprometido com as ideias do seu pai, Inácio Tosta, considerado um dos artífices do Decreto n.ㅇ 1.637, de 05/01/1907. Ver Moura, 1947.

Laborare. Ano IV, Número 6, Jan-Jun/2021, pp. 90-105. ISSN 2595-847X. https://revistalaborare.org/ DOl: https://doi.org/10.33637/2595-847x.2021-65 
Em 1929, o governador Vital Soares, em sua Mensagem anual à Assembleia baiana, menciona a existência de 39 Caixas Rurais e bancos populares. Ressalta, ainda, que através da Lei 2.081, de 6 de junho de 1928, fora estendido aos Bancos Luzatti vantagens fiscais asseguradas ${ }^{15}$ as Caixas Raiffeisen. O relatório detalha, por fim, quais Bancos Populares, Bancos Rurais e Caixas Rurais apresentam melhor desempenho.

Segundo Moura (1947, p.15), das inúmeras Caixas Rurais criadas em decorrência da campanha do governo estadual, apenas quatro tiveram efetivo funcionamento, considerando-as como tentativas governamentais fracassadas. Na interpretação deste autor, no seu texto Notícia do Cooperativismo Brasileiro:

O incremento ao cooperativismo começou, propriamente, a partir de 1941, quando foi fundado um departamento governamental no Estado. Coube-me ser o sistematizador de sua prática, no que pude, felizmente, contar com a colaboração e apoio de dedicados companheiros. Naquela época, tínhamos apenas 22 cooperativas, das quais praticamente $1 / 3$ apenas funcionava. Os elementos estatísticos mais próximos, que no momento disponho, registram que este estado possui 204 cooperativas com 31.587 associados e capital realizado de 7.724.000,00 réis.

Como se pode ver, apesar do aparente insucesso do estímulo governamental ao cooperativismo nos anos vinte do século passado, nova onda de cooperativas ocorre nos anos quarenta ${ }^{16}$. O cooperativismo de crédito que despontava em primeiro lugar foi suplantado pelas cooperativas escolares, também em decorrência de obrigatoriedade estabelecida para as escolas da rede estadual. Simultaneamente, observa-se o crescimento das cooperativas dos produtores de cacau, de energia elétrica, de agricultura e pecuária (MOURA, 1947).

Ainda segundo Moura, no caso do cooperativismo do cacau teve grande significado a disputa em torno do monopólio da exportação do produto, cuja compra da produção era realizada por sete firmas, notadamente, estrangeiras, o que mereceu grande repercussão nos jornais da época. Assim, o Governo Federal resolve criar o Instituto do Cacau, inicialmente funcionando como uma autarquia, em seguida na forma cooperativa e, finalmente, retornando a ser uma autarquia estadual. A criação do Instituto do Cacau tornou estatal o monopólio da aquisição da produção antes privado, contrariando não apenas os interesses das firmas monopolistas, mas principalmente das cooperativas locais que representavam os interesses dos

15 Conforme disposto no Decreto Legislativo n.o 1.764, de 13 de janeiro de 1925.

16 No liuro Bibliografia Brasileira do Cooperativismo (132p.), de Valdiki Moura, há uma menção aos Anais do I Congresso Estadual de Cooperativismo, publicado pelo Departamento de Assistência ao Cooperativismo da Bahia, em 1945. Contudo, não foi possivel, neste estágio da pesquisa, aprofundarmo-nos no tema.

Laborare. Ano IV, Número 6, Jan-Jun/2021, pp. 90-105. ISSN 2595-847X. https://revistalaborare.org/ DOI: https://doi.org/10.33637/2595-847x.2021-65 
produtores. Transformado novamente em Instituto, puderam as cooperativas de cacau, reunidas em duas centrais, ampliar os seus ganhos no comércio internacional.

Valdiki Moura não apenas dirigiu o Departamento de Cooperativismo no Estado, como foi da sua autoria o projeto de lei estadual que estabeleceu a obrigatoriedade da constituição de cooperativas em escolas públicas. Salienta que o objetivo não era impor à coletividade escolar uma organização que por definição é voluntária, mas se tinha em vista "impor ao professorado esta atividade extracurricular, considerada subsidiária e de importância fundamental no preparo da mentalidade infantil" (MOURA, 1947, p.17), e acrescenta:

Segundo dados atualizados, há no estado 120 cooperativas escolares abarcando 5.183 associados, com o capital subscrito de $\$ 17.712,00$. Possivelmente, hoje, esta cifra terá excedido de uma centena de milhar. Essas sociedades se encarregam de adquirir artigos escolares e vestuário para fornecer a preço de custo (MOURA, 1947, p. 16).

Observa-se, que a função pedagógica daquelas cooperativas escolares era prejudicada pelo caráter impositivo da sua criação, prevalecendo a atividade relacionada ao custeio, pelas famílias, de itens que, posteriormente, passaram, em muitos casos, a serem custeados pelo próprio estado.

A criação compulsória de cooperativas escolares possivelmente tenha sido determinante para que em fins do ano de 1958, entre as 883 cooperativas deste gênero no país, 153 estavam instaladas na Bahia (LUZ FILHO, 1960).

Também fruto da ação governamental, cinco "cooperativas de eletricidade" foram constituídas com o objetivo de fornecer energia elétrica para iluminação pública e domiciliar, mas apenas três continuaram funcionando. Nas palavras de Moura: "A Bahia tem sido o campo de experimentação desse tipo, embora seus resultados sejam ainda modestos".

A política governamental expandiu-se para diversas áreas, constituindo, por exemplo, cooperativas culturais, com a oferta de ensino regular em diversos níveis, inclusive profissional, experiência apresentada como exemplo a ser seguido.

A Cooperativa Central Instituto de Pecuária da Bahia também resultou da intervenção estatal e contava com ampla atuação no desenvolvimento da pecuária de corte e de leite, na comercialização de reprodutores, na seleção de gado bovino, na realização de exposições etc.

Laborare. Ano IV, Número 6, Jan-Jun/2021, pp. 90-105. ISSN 2595-847X. https://revistalaborare.org/ DOl: https://doi.org/10.33637/2595-847x.2021-65 


\section{CONSIDERAÇÕES FINAIS}

Importante observar que o estudo empreendido, a despeito dos resultados positivos e do grande número de sociedades cooperativas identificadas preliminarmente, evidencia a ocorrência de dados assistemáticos, com descrição escassa sobre as experiências propriamente ditas.

Destaque-se como marcante a influência das políticas públicas no surgimento de ondas cooperativas - notadamente de crédito, escolares e agropecuários. Contudo, mesmo não tendo sido levantadas informações específicas sobre o processo de formação e de gestão destas cooperativas, há indícios que apontam para uma inconsistência nos fundamentos cooperativistas, sobretudo na emergência da decisão de constituí-las e na autonomia para a gestão.

Segundo Bursztyn (1989, p. 77), especialmente no governo Vargas, passa a predominar no Estado brasileiro a concepção de que as cooperativas seriam "uma forma de enfrentar as dificuldades econômicas herdadas da Primeira Guerra Mundial e da Grande Depressão, que se seguiu à crise de 1929/1930", e para tanto era necessário mantê-las sob o controle e a fiscalização do estado. Para este autor, "a forma autoritária com que o Estado dirige a inseminação artificial do movimento cooperativista no Brasil justifica o caráter de seu desenvolvimento: quantitativo, muito mais do que qualitativo (BURSZTYN, 1989, p. 76)".

Estas considerações devem iluminar a necessária análise sobre o processo de formação de cooperativas na Bahia, sob a tutela do estado. As experiências teriam surgido por força de lei, compulsoriamente, no caso das cooperativas escolares, ou motivadas por estímulos financeiros, no caso das caixas rurais, que apontaram para um baixo nível de sustentabilidade.

Sobre os achados da pesquisa, merecem destaque três fatores. Primeiramente, a existência da Cooperativa de Consumo no Rio de Janeiro, cujos documentos básicos foram divulgados no Jornal do Commercio, edição de 19 de dezembro de 1875, e cuja autorização para funcionamento foi decretada pela Regente Princesa Isabel. Significa dizer que este registro antecipa, em 20 anos, a data consagrada da fundação da primeira cooperativa do Brasil. Da mesma forma, em segundo lugar, antecipa a data de publicação da primeira norma legal sobre o cooperativismo, visto que o Decreto Imperial n. ${ }^{\circ} 6.186$ de 26 de abril de 1876, que autorizou o funcionamento da Cooperativa de Consumo do Rio de Janeiro, é anterior em quase três décadas à Norma legal de 1903.

Laborare. Ano IV, Número 6, Jan-Jun/2021, pp. 90-105. ISSN 2595-847X. https://revistalaborare.org/ DOI: https://doi.org/10.33637/2595-847x.2021-65 
Por fim, em terceiro lugar, cabe anotar um dado efetivamente significativo, noticiado na edição de 4 de março de 1890, do Pequeno Jornal, o resultado da reunião da Sociedade Cooperativa dos Alfaiates, aprovando a reforma do Estatuto e outras medidas administrativas, sugerindo um funcionamento anterior àquela data, da primeira cooperativa baiana.

Não se trata apenas de identificar experiências anteriores, mas ressaltar que as cooperativas começaram efetivamente a existir no Brasil muito antes do que se imaginava, e que surgem de iniciativas autônomas, mesmo que fosse requerida a autorização do poder público.

Com estes elementos, uma nova agenda, de caráter mais qualitativo, se estabelece, com o desafio de conhecer amiúde os fatos cooperativos mais significativos. Considerar que novos estudos podem alavancar as descobertas e enriquecer a história do cooperativismo na Bahia.

\section{REFERÊNCIAS BIBLIOGRÁFICAS}

ACI AMÉRICAS. Aliança Cooperativa Internacional para as Américas. Lei Marco para as cooperativas de América Latina. 1a ed. - San José, Costa Rica, 2009.

BAHIA, Governo da. Catálogo Cooperativas do Estado da Bahia. $1^{\text {a }}$ Edição, Salvador - BA. 158 páginas. 2012.

BRASIL. Ministério da Agricultura, Pecuária e Abastecimento. Evolução do cooperativismo no Brasil : DENACOOP em ação. Brasília: MAPA. 124 p. 2006.

BRITTO, José Saturnino. OS FUNCCIONARIOS E A COOPERAÇÃO. Rio de Janeiro - GB, 1924.

BURSZTYN, M. O poder dos Donos: Planejamento e Clientelismo no Nordeste. Petrópolis. Ed. Vozes, 1985.

LUZ FILHO, Fábio. Cooperativas escolares. Ministério da Agricultura. Serviço de Economia Rural, $5^{\text {a }}$ edição. Rio de Janeiro, GB, 405 p. 1960.

MOURA, Valdiki. Notícia sobre o Cooperativismo brasileiro, Seção de Informações Sociais e Trabalhistas, União Pan-Americana. Washington, D. C. 94 p. Julho, 1947.

. "Bibliografia Brasileira do Cooperativismo": pequeno ensaio de sistematização. Casa do Estudante do Brazil. Rio de Janeiro - GB, 132 P. 1951. 
PINHEIRO, Marcos Antonio Henriques. Cooperativas de crédito: história da evolução normativa no Brasil. 6 ed. - Brasília: BCB, 2008.

SILVA, Eduardo Faria. A ORGANIZAÇÃO DAS COOPERATIVAS BRASILEIRAS E A NEGAÇÃO DO DIREITO FUNDAMENTAL À LIVRE ASSOCIAÇÃO. Dissertação de Mestre no Programa de Pós-graduação em Direito da Universidade Federal do Paraná. Curitiba - PR, 138 pp. 2006.

SISTEMA OCB. Anuário do Cooperativismo Brasileiro. Brasília - DF. 122 pp. 2019.

UNICAFES. União das Cooperativas da Agricultura Familiar e Economia Solidária. http://unicafes.org.br/. 2020

WAKULICZ, GILBERTO, E OLIVEIRA FILHO, JOÃO TELMO DE. LEGISLAÇÃO COOPERATIVISTA. COLÉGIO POLITÉCNICO DA UFSM REDE E-TEC. SANTA MARIA - RS, 2015.

Recebido: 20/10/2020

Revisado: $26 / 11 / 2020$

Aprovado: 08/12/2020 